\title{
The Mutually Reinforcing Relationship between Teaching and Research
}

\author{
Yanfen Gan 1, a, Junliu Zhong ${ }^{2, \text { b }}$, Janson Young, c \\ ${ }^{1}$ School of Information Science and Technology, Guangdong University of Foreign Studies South \\ China Business College, Guangzhou 510545, China;
${ }^{2}$ School of Information Engineering, Guangdong Mechanical \& Electrical College, Guangzhou 510550, China.

aFannygyf@foxmail.com, bJunliuzhong@foxmail.com, cJansonyoung@foxmail.com

\begin{abstract}
Today, teaching and research are two important functions in colleges and universities, so teachers must correctly handle the two's relationship. The author has discussed the dialectical relationship between teaching and research and believes the two are interdependent and mutually reinforcing based on his personal experience from teaching and research practice. It's therefore required of college and university teachers to clearly understand the relationship between teaching and research, combine teaching and research, promote teaching through research, develop research based on teaching, and enhance both their teaching ability and research capability.
\end{abstract}

Keywords: Research; teaching; dialectical relationship; mutually reinforcing.

\section{Introduction}

The competition between various countries has shifted its focus from economy to science and technology today, especially national scientific and technological innovation capability [1]. In this context, colleges and universities are assuming increasingly important tasks as an important place for innovative talent training. And scientific research as one of the basic functions of research universities has developed an increasingly close relationship with teaching and innovative talent training. Accordingly, there's a growing awareness among higher education workers that teaching and research cannot contradict each other or replace each other, besides a growing attention to integrate research into the links of teaching and innovative talent training. Today, with the deepening reform of education and teaching, it has been a top priority in higher education to change traditional teaching model, break traditional teaching pattern, establish a new teaching model that meets the requirements of the times and cultivates innovative talents. To this end, we should take modern teaching ideas and teaching theories as a guide, echo the development strategy of rejuvenating the country and building an innovative country through science, education and human resources, focus on innovative education and scientific research throughout the entire teaching process, and build a three-pronged teaching model involving teaching, research and practice, in order to achieve the cultivation of students' practical and innovative capabilities as well as the improvement of their comprehensive quality and ability.

\section{How Teaching Promotes Research}

We all have such a feeling in daily teaching that teaching practice makes us better digest basic theories; even for those we've studied before, we are bound to think more and deeply once we need to teach students these theories and make sure they understand and grasp these theories. This thinking process that promotes our understanding of basic theories and thus lays a better theoretical basis for our research activities [2].

It is required that teaching be simple but profound. But in actual teaching, it's easy to teach profound theories but quite hard to do that in simple language so that students are able to understand and accept those theories. Teaching of profound theories itself can lay better foundation for research. And teaching in simple language isn't simplifying the issue; instead, it requires an exact grasp of the nature of the issue and represents the concentration and sublimation of knowledge. For this, teachers should broaden their horizons, view the issue from different angles, and analyze them on deeper 
levels, with the purpose to make teaching more effective and reinforce research at the same time. Such a teaching process helps to enhance their theoretical knowledge and leads to a broader set of ideas. It also helps teachers grasp basic theories and thus creates better conditions for research. Meanwhile, students will be encouraged to be active and think out of the box, of whom outstanding ones will raise their own questions and views in addition to listening. During conversations with students, teachers may find themselves greatly inspired by the seemingly unreasonable or unconventional questions asked by students, so as to have further reflections and promote research development.

\section{How Research Supports and Guides Teaching}

It is advocated that professors should undertake basic course teaching for undergraduate students. The basic courses prepare students for advanced ones and seem not profound at all, while professors work on many complex research subjects with limited energy, so why are professors required to undertake basic course teaching? It is precisely because professors are equipped with solid research foundation and can play a positive role if they engage in teaching work.

Take for example digital image processing, a major course designed for undergraduates of the Department of Computer and Information. The course has high prerequisites and difficult content and is highly theoretical and practical. And traditional teaching focuses on theories, introducing and deriving them, emphasizing their concepts and system, but ignoring the steps to practice them, so that students generally feel them very abstract in learning and don't know about their practical application [3]. In order to train the students' innovative awareness and capability, the author enriches the course with new achievements made in the research work and main arguments explained in the scientific papers as an example for illustration and transforms and upgrades them through teaching in order to clarify students' learning objectives, stimulate their learning interest, and inspire their independent thinking and professional thinking. At the same time, the author also introduces research questions into teaching so as to form a teacher-student interaction, stimulate students' innovative inspiration and develop their research capabilities.

In addition to reforming teaching methods, we can raise the level of literacy and knowledge of teachers in order to improve the quality of teaching. While mastering the basics, teachers should practice and apply them into scientific research. Only in this way can they occupy a commanding height, teach simple but profound knowledge, and excite students' interest in learning. In the research work, teachers will always encounter new problems and explore new ideas to solve them. On the one hand, they will gradually bring their accumulated research methods into class consciously or unconsciously, which enable students to learn how to ask questions, analyze them and settle them, instead of just learning book knowledge mechanically. On the other hand, they are telling students not to blindly believe in all the golden rules in textbooks. Indeed book knowledge is very important, but it needs to be constantly replenished and perfected in today's rapid technological advance [4]. And this asks teachers to have a new understanding of the industry's development to be competent at teaching. In fact, there's usually a strong academic atmosphere in good universities which will have a profound impact on the campus culture.

\section{Conclusion}

A great number of college education workers are dedicated to thinking about and exploring the issue of teaching and research and applying the latest practical research results into training of college students, with many good attempts and studies. But only by systematic review of the studies, discovery of the deficiencies, and comprehensive planning of problems to be studied and solved, can we gather the strength of all colleges and universities and establish the operating model and mechanism that adapts to China's characteristics. In the meantime, we can radiate the results to other schools for an early realization of power-driven and all-moving innovative talent training objective as expected by the Ministry of Education. 


\section{Acknowledgements}

This work is supported by partly by the 2015 Guangdong Province Application-oriented Talent Training Demonstration Major of University Teaching Quality and Teaching Reform Project--Computer Science and Technology and Guangdong University of Foreign Studies South China Business College--Guangzhou XinBao software technology co., LTD., college students' off-campus practice teaching base. (YUEGAO HAN [2015] No. 133)

\section{References}

[1]. Hongda Liu, Yong Lu, lanyong Zhang, Integrate scientific research team and scientific research into the present situation of the innovative talents training, Journal of Higher Education, Vol.2 (2016), P26-27.

[2]. Huiqing Zhang, Mingrong Ren, Xuejin Gao, Specialized course teaching and scientific research and practice cultivate innovative talents. Journal of Lanzhou petrochemical vocational and technical college, 2008, 31(5):436-439.

[3]. Lifeng Xing, Zhengyue Song, Xiaodong Zhang. Organic combination of teaching and scientific research and training skills training of innovative talents in the new period, 2009(11):126-128.

[4]. Wancheng Li. Combination of teaching and research is an important way of cultivating innovative talents. Cutting-edge, 2002(4):26-28. 